\title{
WILAYAH JELAJAH DAN AKTIVITAS HARIAN ELANG JAWA (Nisaetus bartelsi STRESEMANN, 1924) DI BUKIT MAYANA KECAMATAN KADUGEDE, KABUPATEN KUNINGAN
}

\author{
Opik Rahmadiana ${ }^{1}$, Toto Supartono ${ }^{2}$, Iing Nasihin ${ }^{3}$ \\ ${ }^{1}$ Program Studi Kehutanan, Fakultas Kehutanan Universitas Kuningan \\ opik.rahmadiana@gmail.com \\ ${ }^{2}$ Program Studi Kehutanan, Fakultas Kehutanan Universitas Kuningan \\ toto.supartono@uniku.ac.id \\ ${ }^{3}$ Program Studi Kehutanan, Fakultas Kehutanan Universitas Kuningan \\ Iing.nasihin@uniku.ac.id
}

\begin{abstract}
Abstrak : Elang jawa (Nisaetus bartelsi) merupakan jenis raptor dengan penyebaran terbatas (endemik). Elang jawa dilindungi oleh Peraturan Menteri Lingkungan Hidup dan Kehutanan Republik Indonesia Nomor P.92 tahun 2018 dan termasuk kategori endangered menurut IUCN Redlist (2017). Tujuan penelitian ini untuk mengetahui wilayah jelajah elang jawa dan aktivitas hariannya. Penelitian dilaksanakan di Bukit Mayana Kecamatan Kadugede, Kabupaten Kuningan selama 4 bulan dari Desember 2017 sampai Maret 2018. Metode yang digunakan yaitu Cooperative Method dan Focal Animal Sampling. Analisis wilayah jelajah menggunakan Minimum Convex Polygon dan Kernel Density Estimation dan analisis deskriptif untuk aktivitas harian. Berdasarkan hasil penelitian dan analisis didapatkan wilayah jelajah elang jawa dengan MCP individu Maya dan Yana masing-masing seluas 79.8 ha dan 189.9 serta KDE seluas 118.6 ha dan 180.6 ha. Aktivitas harian elang jawa di bukit Mayana yang paling banyak terlihat adalah terbang dengan presentase $79 \%$ sedangkan ketika tengger hanya sebesar $21 \%$. Intensitas terbang paling tinggi mulai dari jam 09:00-11:30.
\end{abstract}

Kata Kunci: Aktivitas harian, Wilayah jelajah, kernel density estimation, , Nisaetus bartelsi

\section{PENDAHULUAN}

Elang jawa (Nisaetus bartelsi) merupakan jenis raptor dengan penyebaran terbatas (endemik). Spesies ini terbatas pada sisa-sisa hutan terakhir di Pulau Jawa yang berpenduduk padat, karena kawasan hutan alam yang terus menurun di Jawa dan meningkatnya perdagangan burung, spesies ini dianggap terancam punah (Endangered) (IUCN Redlist, 2017).

Pemerintah Indonesia telah secara resmi mengumumkan elang jawa sebagai satu dari 25 spesies prioritas utama yang harus ditingkatkan populasinya sebesar $10 \%$ pada periode 2015 sampai 2019 (SK Dirjen PHKA, 2015). Elang jawa dilindungi di Indonesia sejak tahun 1990 melalui Undang-Undang Republik Indonesia Nomor 5 Tahun 1990 tentang Konservasi Sumber Daya Alam Hayati dan Ekosistemnya serta Peraturan Menteri Lingkungan Hidup dan Kehutanan RI Nomor P.92 tahun 2018 tentang Jenis Tunbuhan dan Satwa yang Dilindungi.

Habitat elang jawa terbatas pada hutan alam (Sozer et al., 1998). Elang jawa juga menggunakan hutan sekunder untuk area berburu dan persawahan yang terletak dekat dengan hutan hujan primer luas yang mempengaruhi keberhasilan pengembangbiakannya (Rov et al, 1997 dalam Setiadi et al, 2000). Seperti hutan tempat tinggalnya, habitat elang jawa sangat terfragmentasi dan mungkin terisolasi satu sama lain (van Balen et al 1999).

Bukit Mayana yang tidak termasuk kawasan konservasi merupakan salah satu habitat elang jawa selain Taman Nasional Gunung Ciremai dengan luasan hutan alamnya yang sangat kecil di Kabupaten Kuningan (Irawan pers. comm 2015). Oleh karena itu perlu dilakukan penelitian untuk menambah data dasar biologi dan ekologi elang jawa yang akan mendukung program pelestarian elang jawa serta sebagai bahan pertimbangan dalam menentukan kebijakan dalam melakukan pengelolaan kawasan yang berhubungan dengan kelestarian elang jawa di kawasan non konservasi di Kabupaten Kuningan. Penelitian ini difokuskan untuk mengkaji wilayah jelajah dan aktivitas harian elang jawa

\section{METODOLOGI PENELITIAN}

Penelitian dilaksanakan di Bukit Mayana Kecamatan Kadugede Kabupaten Kuningan pada bulan Desember 2017 sampai dengan bulan Maret 2018. Alat yang digunalan adalah peta topografi Bukit Mayana, binokuler, kamera digital, GPS, kompas bidik, penggaris mistar, penunjuk waktu, alat komunikasi, alat tulis, buku Panduan Survei Lapangan dan Pemantauan Burung-burung 
Pemangsa (Prawiradilaga et al 2003) serta buku Panduan Inventarisasi Elang Jawa Nisaetus bartelsi (Sozer et al 2012), dan bahannya yaitu elang jawa liar yang ada di Bukit Mayana

Pengamatan dilaksanakan secara bersamaan pada beberapa titik yang sudah ditentukan untuk memudahkan pengamatan. Metode ini disebut cooperative method karena dilakukan secara bersama oleh beberapa pengamat terhadap objek yang sama yaitu elang jawa dan elang jenis lain yang terlihat di lokasi pengamatan Bukit Mayana (Yamazaki pers. comm dalam Setiadi et al 2000). Pengamatan perilaku harian elang jawa dengan menggunakan metode focal animal sampling. Pencatatan dilakukan setiap sepuluh menit sekali.

Pengamatan dilakukan pada 3 titik pengamatan (standing point) yang sudah ditentukan, dengan dibantu oleh pengamat lain yang melakukan pengamatan di lokasi yang berbeda pada waktu yang sama. Pengamatan dilakukan 16 kali pada setiap titik pengamtan selama 4 bulan, mulai jam 07.00 sampai jam 16.00 .

Jenis data yang diambil yaitu wilayah jelajah dan perilaku harian elang jawa. Data yang dicatat saat pengamatan elang jawa adalah identifikasi individu elang jawa (jenis kelamin, kelas umur, dan ciri-ciri fisik yang terlihat seperti adanya molting (bulu yang meluruh atau tidak), jumlah individu, titik/sudut teramatinya individu elang jawa tersebut pada peta, jam perjumpaan dan lamanya aktivitas terjadi. Untuk data perilaku harian elang jawa yang dicatat yaitu melakukan aktivitas bertengger, terbang (soaring, gliding, display), berburu, makan, mengasuh. Selain itu juga dicatat jenis-jenis elang lainnya yang terlihat selama pengamatan.

Analisis yang digunakan untuk menduga luas wilayah jelajah elang jawa adalah MCP (Minimum Convex Polygon) dan KDE (Kernel Density Estimation). Wilayah jelajah elang jawa dianalisis secara kuantitatif dan deskriptif kualitatif. Menurut Sitorus (2016) analisis untuk persentase aktivitas elang jawa dengan rumus sebagai berikut: $\%$ perilaku $=\frac{X}{Y} x 100 \%$ dimana $\mathrm{X}$ (frekuensi satu perilaku yang diamati dalam pengamatan) dan Y (frekuensi seluruh perilaku yang diamati dalam pengamatan).

\section{HASIL DAN PEMBAHASAN Wilayah Jelajah}

Elang jawa di Bukit Mayana teridentifikasi pertama kali pada tahun 2013 (Irawan 2017, pers. comm). Selama penelitian berlangsung elang jawa di Bukit Mayana yang teramati yaitu sebanyak 3 individu yang merupakan satu keluarga dengan komposisi 2 individu dewasa (jantan dan betina) serta 1 elang jawa remaja yang berumur $\pm 1,5$ tahun. Umur elang jawa remaja dapat diketahui karena sudah terpantau sejak bulan November 2016 yang diperkirakan sudah berumur 4 bulan. Anakan elang jawa hanya teramati sekali selama pengamatan berlangsung yaitu pada minggu awal bulan januari 2018. Peneliti berasumsi bahwa elang jawa remaja tersebut sudah berpindah tempat atau sudah lepas masa sapihnya.

Populasi elang jawa di Bukit Mayana sangat terancam karena cukup tingginya aktivitas manusia di habitat elang jawa tersebut. Selain itu elang jawa di Bukit Mayana sudah beberapa kali mengalami perburuan sejak pertama kali teridentifikasi. Menurut Irawan (2017) pers.comm) bahwa elang jawa di Bukit Mayana mengalami perburuan yaitu pada tahun 2013 dan 2015. Hal ini diketahui karena pada tahun 2013 salah seorang warga di Desa Ciketak memiliki anakan elang jawa yang di sita oleh Balai Besar Konservasi Sumber Daya Alam Jawa Barat (BBKSDA) yang kemudian di rehabilitasi dan dilepasliarkan di Taman Nasional Gunung Ciremai (TNGC) dan diberi nama Lambo.

Pada bulan Juni 2015 anakan elang jawa hilang dari sarang karena pada pengamatan bulan Mei anakan elang jawa di Bukit Mayana sudah menetas, namun setelah itu tidak dilakukan lagi pengamatan selama hampir satu bulan. Saat dilakukan pengamatan kembali anakan elang jawa diketahui sudah tidak ada disekitar sarang dengan kondisi sarang sudah rusak, diduga bahwa elang jawa tersebut ada yang memburu (Irawan, 2017 pers. comm). Elang jawa dalam penelitian ini dibedakan dan kemudian di beri nama berdasarkan ciri fisiknya yaitu Yana untuk elang jawa yang tidak molting, dan Maya untuk yang memiliki molting di sayapnya..

Habitat elang jawa di Bukit Mayana dikelilingi oleh pemukiman penduduk dari berbagai sisinya, sehingga menyebabkan terisolasinya elang jawa tersebut. Tipe tutupan lahan di sekitar habitat elang jawa yaitu hutan alam, hutan tanaman, lahan terbuka (semak belukar), perkebunan (palawija), sawah, serta pemukiman penduduk.

Tutupan lahan yang berperan penting untuk kelangsungan hidup elang jawa adalah hutan alam. Hal ini diketahui karena selama penelitian berlangusng sebagian besar aktivitas elang jawa dilakukan di hutan alam yang merupakan sebagai tempat berlindung, tempat isirahat, berburu, dan 
berkembang biak. Harits (2016) juga menyebutkan bahwa hutan alam menjadi habitat utama elang jawa karena preferensi khusus terhadap pohon yang akan dijadikan sarang.

Aktivitas elang jawa di tutupan lahan lain hanya digunakan sebagai jalur lintasan saja kecuali pada hutan tanaman yang beberapa kali terlihat tengger di pohon jabon (Neolamarckia cadamba) dan kihiang (Albizia procera), meskipun di hutan tanaman tersebut masih terdapat beberapa pohon ficus sp. besar dan masih cukup dekat dengan hutan alam. Di hutan alam Bukit Mayana terdapat 43 jenis pohon, yang di dominasi oleh genus ficus (Alfiyasin, 2018).

Hutan alam di Bukit Mayana hanya seluas 15 ha, sehingga habitat elang jawa sangat terfragmentasi dan berbatasan langsung dengan hutan tanaman dengan aktivitas manusia yang cukup tinggi. Bukit Mayana sebelah Utara merupakan daerah dengan frekuensi aktivitas elang jawa paling tinggi. Habitat ideal elang jawa adalah hutan alam/primer yang luas (Sozer et al, 2012). Namun dengan kondisi habitat elang jawa di Bukit Mayana hal ini menandakan bahwa elang jawa bisa bertahan hidup di kondisi hutan alam atau primer yang cukup kecil (15 ha).

Beberapa burung pemangsa jenis lain yang tercatat selama penelitian berlangsung di Bukit Mayana yaitu elang-ular bido (Spilornis cheela), elang brontok (Nisaetus cirrhatus), elang hitam (Ictinaetus malaiensis), sikep-madu asia (Pernis ptilorhynchus (ras penetap dan migran), dan elang laut perut putih (Haliaeetus leucogaster).

Elang-laut perut putih kemungkinan besar adalah elang lepasan yang berada di sekitar Waduk Darma, hal ini dikarenakan arah datang dan pergi elang tersebut dari arah Barat, dimana letak Waduk Darma berada di sebelah barat lokasi penelitian.

Sikep-madu asia sering terlihat di sebelah Selatan Bukit Mayana untuk ras migran, sedangkan untuk ras jawa yang memiliki jambul terlihat di sebelah Selatan hingga Utara. Sikepmadu asia ras jawa yang terlihat di Bukit Mayana terdapat satu pasang.

Elang brontok di Bukit Mayana teramati di sebelah Selatan bukit. Elang brontok terlihat melakukan perburuan di areal dengan vegetasi yang masih jarang dan pendek, dimana pada daerah tersebut terdapat burung-burung kecil. Areal terbuka dengan heterogenitas yang rendah tetap mampu menyediakan sumberdaya pakan bagi elang brontok (Sitorus, 2016).

Elang hitam biasanya terlihat di sebelah Selatan dan Timur Bukit Mayana. Lokasi yang sering dikunjungi atau teramatinya elang hitam adalah hutan tanaman dan daerah semak belukar. Elang hitam biasanya terlihat berpasangan dan terbang cukup rendah.

Elang-ular bido adalah elang yang paling umum atau paling banyak terlihat ketika pengamatan sedang berlangsung. Tutupan lahan yang digunakan untuk aktivitas elang-ular bido adalah semua jenis tutupan lahan. Aktivitas berburu juga terlihat di perbatasan hutan alam dan hutan tanaman yang termasuk daerah inti elang jawa.

Persaingan dalam mendapatkan sumberdaya makanan kemungkinan besar dapat terjadi diantara elang jawa, elang brontok, elang hitam, dan sikep madu asia jika keberadaan sumberdaya pakan terbatas. Namun berdasarkan hasil penelitian belum bisa dipastikan adanya persaingan dikarenakan tidak teramatinya pengusiran antar elang tersebut. Seperti halnya elang ular bido yang sering terlihat berada di sekitar elang jawa yang sedang beraktivitas, namun tidak ada serangan atau interaksi pengusiran dari keduanya. Sementara itu untuk elang brontok dan elang hitam persaingan terjadi kemungkinan kecil karena dari hasil pengamatan, habitat utama keduanya bukan di Bukit Mayana. Sedangkan jika dengan sikep madu asia juga kemungkinannya kecil dikarenakan menurut Prawiradilaga et al (2003) bahwa pakan sikep madu asia berupa ulat, dan anakan tawon atau lebah

Hasil penelitian dari bulan Desember 2017 Maret 2018 bahwa luas wilayah jelajah dengan metode analisis minimum convex polygon (MCP) untuk individu Maya 79.8 ha, sedangkan untuk individu Yana 189.9 ha. Sedangkan dari hasil analisis dengan menggunakan kernel density estimation (KDE) 95\% didapatkan luas wilayah jelajah individu Maya yaitu 118.6 ha dan untuk individu Yana seluas 180.6 ha. Sehingga didapatkan rata-rata untuk dua metode analisis dan sepasang elang jawa yaitu 142.2 ha. Peta wilayah jelajah elang jawa Yana bisa dilihat pada gambar 3.1 dan Maya pada gambar 3.2. 


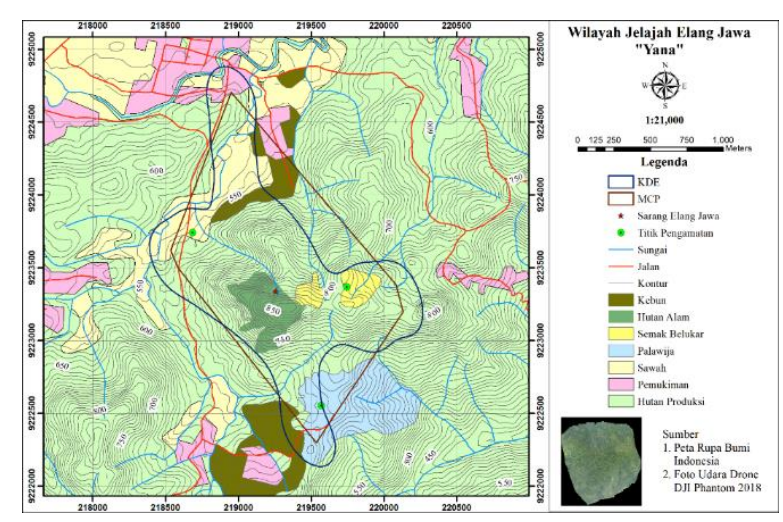

Gambar 1. Wilayah jelajah elang jawa Yana

Perkiraan wilayah jelajah hasil dari penelitian yang terdahulu terdapat berbagai ukuran. Jika dibandingkan dengan hasil penelitian lainnya bahwa wilayah jelajah elang jawa di Bukit Mayana lebih kecil. Seperti luasan wilayah jelajah elang jawa di Gunung Kendeng dengan rata-rata 206 ha dan 916 ha (Widodo 2004, Kuswandono et al 2003) dan 530 ha (Gjershaug et al 2004), 500 ha (Røv et al 1997 dalam Setiadi et al 2000, van Balen et al 2001) yang diperkirakan berdasarkan pengamatan langsung. Wilayah jelajah satu individu jantan sebagaimana ditentukan oleh radio telemetri diperkirakan hanya 300 ha (Gjershaug et al 2004). Sementara ukuran yang lebih besar dihitung berdasarkan perkiraan kepadatan populasi (Thiollay \& Meyburg 1988, Meyburg et al 1989, Sozer dan Nijman 1995), ukuran yang lebih kecil diperkirakan berdasarkan pada individu yang diamati.

Ada beberapa hal yang mengakibatkan perbedaan dari luas wilayah jelajah diantaranya adalah lamanya waktu penelitian dan metode yang digunakan. Kuswandono et al (2003) menyatakan bahwa aktivitas tertinggi elang jawa yaitu pada bulan September, karena pada bulan tersebut merupakan awal musim hujan, dimana biasanya terjadi aktivitas berkembang biak dan pemeliharaan anakan. Selain itu menurut Afianto (1999) pada burung-burung pemangsa seperti elang, wilayah jelajah akan selalu berubah luasnya pada periode musim yang berbeda, sehingga tidak dapat disimpulkan bahwa luasan tersebut merupakan areal jelajah sepanjang hidupnya.

Bukit Mayana dikelilingi oleh pemukiman dan hutan tanaman. Rov et al (1997) dalam Setiadi et al (2000) menyebutkan bahwa elang jawa memanfaatkan hutan sekunder untuk berburu dan bersarang. Tutupan lahan yang menjadi wilayah jelajah elang jawa yaitu hutan alam, hutan tanaman, sawah, semak belukar, dan pemukiman.
Luas hutan alam Bukit Mayana hanya 15 ha dan berdekatan dengan aktivtas manusia namun elang jawa masih bisa berkembang biak dengan baik. Hal ini menunjukkan bahwa meskipun kecil luasan hutan alamnya namun masih bisa mendukung populasi elang jawa. Berbeda dengan Sozer et al (2012), meskipun sarang banyak dijumpai di sekitar hutan primer dan habitat yang terganggu, akan tetapi lokasi tersebut harus dekat dengan hutan primer yang luas untuk kebutuhan berburu.

Kondisi Bukit Mayana di sebelah Utara, Selatan dan Barat lerengnya curam sedangkan sebelah Timur berupa punggungan, namun elang jawa lebih banyak menghabiskan waktunya di lereng Utara. Sarang elang jawa juga terletak di sebelah Utara, hal ini yang menjadikan perjumpaan di lereng Utara lebih banyak di bandingkan lokasi lainnya. Keberadaan sarang di lereng Utara dikarenakan terdapat lembahan yang terdapat aliran sungai kecil. Afianto (1999) menyebutkan bahwa karakteristik sarang elang jawa adalah daerah lembah dengan kemiringan yang mencapai $86^{\circ}$. Habitat normal elang jawa yang dijadikan tempat bersarang dan teritorinya merupakan daerah dengan kelerengan yang curam, yang terletak baik dihutan tropis dataran rendah atau hutan hujan basah dataran rendah dan tinggi (Becking 1989 dalam Utami 2002). Elang jawa sering ditemukan di daerah pegunungan dan berbukit bukit, jarang ditemui di tempat yang datar (van Balen et al 1999).

Habitat yang terfragmentasi mempengaruhi wilayah jelajah elang jawa di Bukit Mayana. Elang jawa merupakan elang yang malas terbang, karena dari hasil penelitian bahwa elang jawa di Bukit Mayana jarang sekali terbang jauh. Hal ini dilakukan untuk menghemat energi. Pada daerah berlembah, saat elang jawa akan melakukan aktifitas terbang, individu elang jawa hanya perlu meluncur yang dilanjutkan dengan soaring atau terbang lurus tanpa mengepakan sayap yang hanya menggunakan thermal. Kegiatan efisiensi energi dilakukan karena ukuran tubuh elang jawa cukup besar, maka jika melakukan aktifitas terbang dengan melakukan gerakan mengepak sayap akan mengeluarkan energi yang lebih besar (Widodo, 2004).

Selain itu keberadaan pakan juga sangat mempengaruhi luas wilayah jelajah. Prawiradilaga (1999) menyatakan bahwa mangsa yang paling disukai elang jawa adalah bajing dan tupai. Sedangkan menurut Sitorus (2016), ciri khas areal buru elang jawa yaitu tersedia potensi mangsa yang beragam dan melimpah seperti 
jelarang ( $R$. bicolor), bajing (Callosciurus notatus) dan ayam hutan (G. gallus). Potensi pakan di hutan alam Bukit Mayana berdasarkan hasil penelitian Alfiyasin (2018), terdapat sembilan jenis burung, lima jenis mamalia diantaranya bajing kelapa (Callosciurus notatus), tupai (Tupaia javanica) dan jelarang (Ratufa bicolor), serta tiga jenis reptil.

Di dalam wilayah jelajah elang jawa di Bukit Mayana juga terdapat beberapa elang jenis lain yang beraktivitas diantaranya elang ular bido, elang brontok, sikep madu asia, elang hitam. Hal ini menjadikan adanya potensi persaingan dalam mencari pakan, terutama dengan jenis elang ular bido yang pernah teramati sedang melakukan perburuan di areal berburu elang jawa.

Elang ular bido merupakan elang yang paling sering teramati dan paling banyak jumlah individunya selama penelitian berlangsung, selain itu elang ular bido hampir menggunakan seluruh bagian dari wilayah jelajah elang jawa. Elang hitam terlihat di daerah semak belukar dan hutan tanaman sebelah timur dan Selatan Bukit Mayana. Sedangkan sikep madu asia biasanya teramati di sebelah selatan hingga utara.

Elang brontok biasanya teramati di sebelah selatan yang merupakan daerah dengan tutupan hutan alam dan hutan tanaman yang vegetasinya masih jarang serta dan juga lahan palawija. Areal terbuka juga merupakan areal buru elang brontok (Sitorus, 2016). Menurut Hoogerwerf (1949) bahwa sumberdaya yang dibutuhkan elang brontok dan elang jawa hampir sama karena dari genus yang sama. Hal ini mendukung dengan apa yang ditemukan selama penelitian bahwa elang jawa jarang terlihat di sebelah Selatan Bukit Mayana

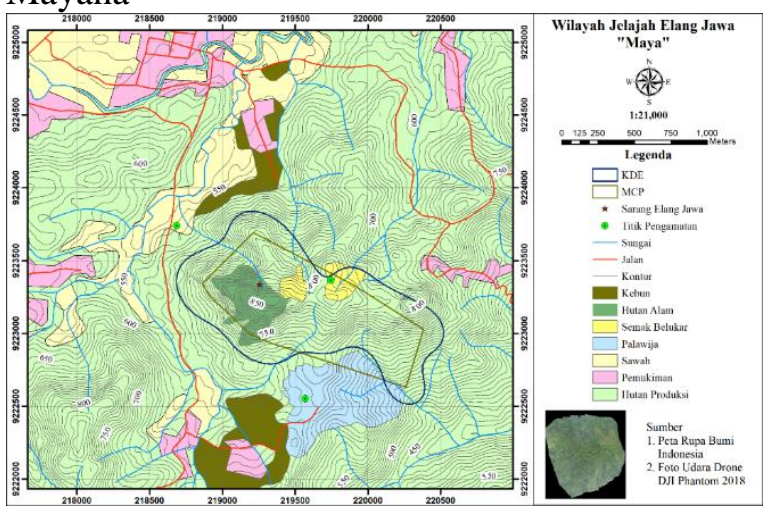

Gambar 2. Wilayah jelajah elang jawa Maya

Daerah inti merupakan polygon yang dihasilkan dari analisis wilayah jelajah dengan metode $\mathrm{KDE} 50 \%$. Hasil dari analisis metode ini yaitu daerah inti individu Yana seluas 31.1 ha sedangkan individu Maya 22.3 ha. Daerah inti bisa disebut juga sebagai daerah yang paling sering dikunjungi satwa (Gambar 3.3).

Daerah inti elang jawa di Bukit Mayana berada pada areal hutan alam dan hutan produksi campuran. Meskipun intensitas aktivitas elang jawa lebih banyak di lakukan pada hutan alam dan daerah tepi. Penggunaan hutan produksi campuran diasumsikan karena terbatasnya hutan alam yang ada di Bukit Mayana. Selain itu pada hutan campuran masih terdapat juga beberapa emergent tree. Areal buru ditentukan dari frekuensi perjumpaan rata-rata lebih dari tiga kali pada lokasi yang sama. Elang jawa dalam melakukan perburuannya dengan teknik perch hunting, yaitu dari dahan ke dahan dan ambush hunting yaitu berburu di daerah terbuka (Utami 2002). Berdasarkan hasil penelitian tercatat 3 kali elang jawa sedang melakukan aktivitas berburu. Areal berburu elang jawa di Bukit Mayana meliputi hutan tanaman dan hutan alam dengan luas 12,8 ha (Gambar 4).

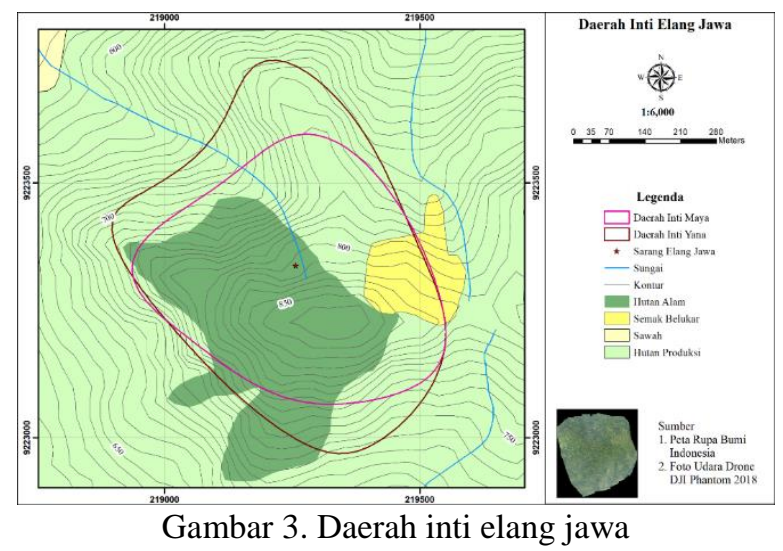

Daerah teritori elang jawa didasarkan pada adanya aktivitas mempertahankan suatu daerah dengan terlihatnya penyerangan terhadap elang jenis lain. Selama penelitian berlangsung aktivitas penyerangan atau pengusiran terhadap jenis lain hanya terlihat satu kali. Daerah teritori elang jawa di Bukit Mayana adalah seluas 2.1 ha (gambar 4).

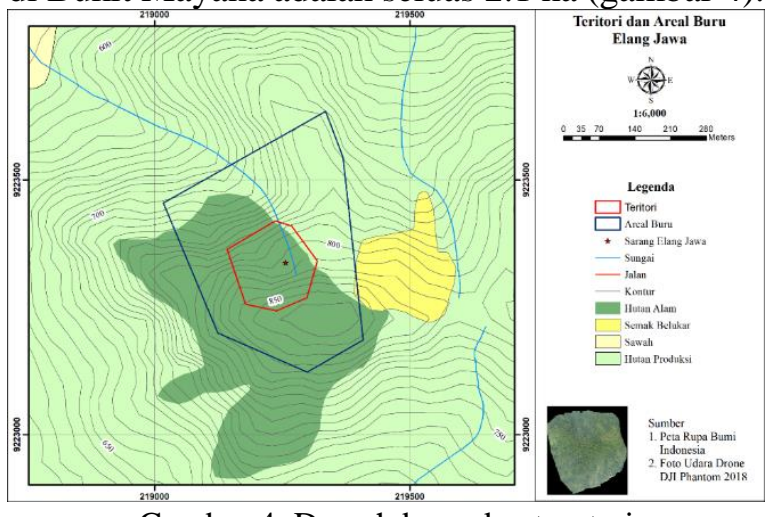

Gambar 4. Daerah buru dan teroteri 


\section{Aktivitas Harian}

Aktivitas harian elang jawa yang teramati adalah aktivitas terbang, tengger, bersuara dan interaksi. Aktivitas terbang merupakan aktivitas yang paling banyak teramati dibandingkan aktivitas lainnya, meskipun pada dasarnya elang jawa merupakan jenis elang yang menghabiskan waktunya lebih banyak untuk bertengger dalam sehari-harinya. Afianto (1999) yang menyatakan bahwa elang jawa menghabiskan $57.23 \%$ waktu hariannya untuk bertengger dan sisanya untuk terbang serta berburu. Gliding dan soaring adalah perilaku terbang yang paling banyak teramati. Perilaku ini dimaksudkan untuk menghemat energi saat terbang, karena perilaku terbang semua jenis elang biasanya mengandalkan energi thermal, angin, dan udara yang melambung keatas (Widodo, 2004).

Berdasarkan hasil dari penelitian selama empat bulan mulai dari Desember 2017 - Maret 2018 aktivitas elang jawa yang ada di Bukit Mayana biasanya terlihat mulai jam 08.30 WIB dan pada sore hari termati pada jam 15.30 WIB. Selama penelitian berlangsung elang jawa lebih banyak terlihat ketika terbang dengan presentase $79 \%$ sedangkan ketika tengger hanya sebesar $21 \%$ (Gambar 3.5). Frekuensi aktivitas tertinggi yang terlihat selama penelitian yaitu pada jam 09.01 11.30 dengan total perjumpan sebanyak 27 kali (Gambar 3.6). Dalam satu hari pengamatan durasi teramatinya elang jawa mulai dari 13 menit sampai dengan 1 jam 26 menit.

Aktivitas terbang lebih banyak terlihat dikarenakan elang jawa lebih banyak beraktivitas di dalam tajuk atau hutan sedangkan penglihatan pengamat terbatas karena terhalangi tajuk dan hanya memakai binokuler. Hal ini sesuai dengan pendapat Nijman dan Sozer (1998) yang menyatakan bahwa raptor hutan tropis sulit dilihat di hutan, kecuali saat periode cahaya yang kuat

Aktivitas terbang dapat dilihat ketika cuaca sedang hangat dan angin bertiup cukup. Selama cuaca baik, kegiatan sehari-hari biasanya dimulai dengan soaring. Soaring dapat dilakukan oleh individu atau pasangan bersama-sama atau pasangan bersama dengan anakan yang masih dalam masa sapih (Prawiradilaga, 2006).

Perilaku terbang yang terlihat ketika pengamatan yaitu terbang berputar keatas tanpa mengepakan sayap (soaring), terbang meluncur (gliding), terbang mengepakan sayap (flapping), menukik (diving), terbang beradu cakar bersama pasangan (display talon), display talon dengan jenis lain, terbang dengan melihat kebawah, dan terbang sambil bersuara. Perilaku terbang yang paling sering teramati selama penelitian berlangsung yaitu gliding dan soaring. Aktivitas terbang bersama sepasang elang jawa juga terlihat tujuh kali selama penelitian berlangsung.

Menurut Widodo (2004) menyatakan bahwa perilaku khas burung pemangsa khususnya elang jawa yaitu soaring dan undulating atau display talon. Aktivitas terbang elang jawa di Bukit Mayana biasanya sering teramati ketika suhu udara mulai hangat yaitu sekitar jam 09.00 WIB. Hal ini berlaku juga untuk elang jenis lainnya, sedangkan ketika kurang dari jam 09.00 perjumpaan semua jenis elang di Bukit Mayana sangat rendah.

Tengger adalah suatu perilaku berdiri tegak dengan kaki bertumpu pada tenggeran. Elang jawa di Bukit Mayana biasanya bertengger hanya di beberapa jenis pohon. Pohon yang digunakan elang jawa bertengger berdasarkan hasil penelitian yaitu pohon ficus sp, kihiang (Albizia procera), benda (Artocarpus elasticus), jabon (Neolamarckia cadamba), salam (Syzygium polyanthum), dan kadoya (Dysoxylum gaudichaudianum). Dari jenis-jenis pohon tersebut biasanya cabang yang digunakan untuk tengger adalah cabang yang tegak lurus. Seperti menurut Utami (2002) yang menyatakan bahwa elang jawa rata-rata memilih cabang pohon yang tegak lurus dengan batang utamanya $\left( \pm 90{ }^{\circ}\right)$ untuk bertengger, mengincar mangsa dan memakan mangsa yang ditangkap.

Pohon benda, ficus $s p$ dan salam termasuk strata A, kihiang, kadoya dan jabon termasuk strata B. Penggunaan pohon oleh elang jawa fokus pada emergent tree meskipun bukan jenis dominan. Afianto (1999) yang menyebutkan bahwa elang jawa menggunakan emergent tree sebab memudahkan elang jawa terbang meluncur (gliding) dari tempat tengger. Selain pohon yang berdaun elang jawa tercatat menggunakan pohon mati untuk bertengger.

Pohon ficus merupakan jenis pohon yang paling sering digunakan dan paling lama durasinya. Waktu paling lama ketika elang jawa tengger adalah 1 jam 20 menit pada pohon ficus $s p$, dan ficus tersebut merupakan tempat favorit elang jawa di Bukit Mayana tengger yang memberikan pandangan paling luas terhadap daerah sekitarnya, yang bertujuan untuk memudahkan dalam memonitoring daerah teritori maupun satwa yang akan diburu.

Perilaku ketika bertengger yang teramati adalah menyelisik, berdiri santai, melihat ke kiri dan ke kanan, melihat untuk berburu, menggerakan ekor, pindah tempat tengger, mengangkat sayap, 
bertengger bersama pasangan dan beradu cakar. Perilaku bertengger bersama pasangan tejadi setelah mereka melakukan terbang bersama dan saling bersuara dengan nada gli-iiik dua kali. Saat bertengger aktivitas elang jawa paling sering yaitu berdiri santai, melihat ke kiri dan ke kanan, serta melihat kebawah seperti akan berburu.

Berdasarakan penelitian bahwa elang jawa di Bukit Mayana menggunakan tutupan lahan hutan alam dan hutan produksi campuran untuk areal berburu. Menurut Afianto (1999), bahwa rata-rata penggunaan waktu di alam dalam satu hari untuk berburu dan makan sebesar 18\%. Selama penelitian elang jawa di Bukit Mayana terlihat 3 kali sedang melakukan perburuan. Elang jawa tersebut melakukan perburuan dengan teknik menyambar mangsanya dari dahan ke dahan (perch hunting). Namun data mengenai hasil buruannya tidak didapatkan. Kemungkinan besar elang tersebut menikmati hasil buruannya tidak ditempat biasa tengger yang mudah teramati. Selain itu keterbatasan alat penelitian yang hanya menggunakan binokuler juga mempengaruhi.

Aktivitas berburu sangat penting dilakukan oleh burung pemangsa untuk pemenuhan kebutuhan energinya. Selain itu pemangsaan sangat penting untuk keseimbangan ekosistem sehingga satwa mangsa akan terkendali jumlah populasinya.

Sozer et al (2012) menyatakan bahwa jenis suara yang telah teridentifikasi adalah sebanyak empat jenis suara dan elang jawa sering bersuara pada masa berbiak dan suara ini dapat terdengar dari jarak jauh. Hal ini sama dengan data yang didapatkan dari penelitian bahwa elang jawa merupakan jenis elang yang sangat jarang bersuara.

Berdasarkan hasil penelitian elang jawa di Bukit Mayana terdengar bersuara sebanyak lima kali, dua diantaranya perjumpaan tidak langsung. Catatan pertama selama penelitian yaitu pada bulan Januari 2018, ketika itu elang jawa terlihat sedang tengger di perbatasan antara hutan alam dan hutan tanaman namun karena melihat aktivitas manusia sehingga elang jawa tersebut bersuara seperti calling dengan nada gli-iik beberapa kali sambil terbang. Nada seperti itu biasanya dikeluarkan ketika elang jawa tersebut merasa terancam (Sozer et al, 2012).

Interaksi sosial elang jawa di Bukit Mayana yang terlihat selama penelitian berlangsung hanya beberapa kali. Interaksi sosial yang terlihat yaitu ketika sepasang elang jawa tersebut terbang bersama dan beradu cakar. Interaksi dengan elang jenis lain juga terlihat satu kali perjumpaan dan interaksi yang terlihat adalah display talon atau beradu cakar, hanya saja jenis elang tersebut tidak teridentifikasi karena interaksi berlangsung dengan cepat. Hal ini diduga adalah bentuk pengusiran oleh elang jawa untuk mempertahankan teritorinya

\section{Implikasi Konservasi}

Berdasarkan hasil penelitian bahwa elang jawa di bukit mayana wilayah jelajahnya yaitu hutan alam, hutan tanaman, sawah, semak belukar, dan pemukiman. Namun daerah inti atau daerah yang sering digunakan elang jawa dan areal berburunya adalah hutan alam dan hutan produksi. Selain itu potensi pakan juga cukup mendukung pada kedua tutupan lahan tersebut. Khusus hutan alam di Bukit Mayana sangat penting dikarenakan sebagai tempat keberadaan sarang sehingga terjadinya perkembang biakan, sebagai tempat berlindung dan beristirahat elang jawa.

Hutan alam Bukit Mayana yang luasnya hanya 15 ha menandakan bahwa elang jawa tidak selalu menempati hutan primer atau alam yang luas. Oleh karena itu perlu dilakukan penelitian atau survey-survey mengenai keberadaan elang jawa di hutan-hutan lain dengan kondisi habitat yang menyerupai habitat elang jawa pada umumnya, terutama pada daerah-daerah hutan non kawasan konservasi. Selain itu perlindungan terhadap habitat elang jawa di kawasan non konservasi juga perlu diperhatikan, dengan demikian peningkatan populasi elang jawa kemungkinan besar akan berhasil.

Ancaman perburuan juga sangat rawan mengingat sudah terjadi dua kali anakan elang jawa diburu. Namun ancaman perburuan tidak hanya pada elang jawa saja, satwa mangsa pun rawan terhadap perburuan. Oleh karena itu pelibatan masyarakat sangat diperlukan dalam upaya-upaya perlindungan terhadap elang jawa dan habitatnya serta satwa mangsa untuk mendukung kelangsungan hidup elang jawa di bukit mayana. Penyadar tahuan juga diperlukan mengenai manfaat keberadaan elang jawa dan UU maupun peraturan-peraturan yang melindungi elang jawa. Sehingga masyarakat sadar dan ikut serta melindungi elang jawa dari ancaman perburuan maupun kerusakan habitat dan perburuan pakan.

Beberapa manfaat ekonomi elang jawa yaitu bisa dijadikan objek wisata minat khusus seperti birdwatching dan fotografi satwa liar. Hal ini merupakan manfaat ekonomi yang berkelanjutan, berbeda halnya ketika masih diburu yang hanya 
memberikan dampak ekonomi sekali dan ruang lingkup yang sempit. Namun harus tetap memperhatikan etika-etika dalam pengamatan hidupan liar agar tidak mengganggu aktivitas elang jawa itu sendiri.

\section{SIMPULAN}

Wilayah jelajah dengan metode analisis MCP untuk individu Maya 79.8 ha dan individu Yana 189.9 ha. Sedangkan dari hasil analisis KDE 95\% didapatkan luas wilayah jelajah individu Maya yaitu 118.6 ha dan untuk individu Yana seluas 180.6 ha. Sehingga didapatkan rata-rata wilayah jelajahnya yaitu 142.2 ha. Daerah inti individu Yana 31.1 ha, sedangkan individu Maya 22.3 ha.

Aktivitas harian elang jawa di Bukit Mayana yang paling banyak terlihat adalah terbang dengan presentase $79 \%$ sedangkan ketika tengger hanya sebesar $21 \%$. Intensitas terbang paling tinggi adalah dari jam 09-00 WIB sampai dengan jam 11.30 WIB. Sementara di waktu lainnya elang jawa jarang terlihat

\section{REFERENSI}

Afianto, M.Y., J.B. Hernowo, dan D.M. Prawiradilaga. 1999. Aplikasi Penggunaan Radio Telemetry Pada Pendugaan Karakteristik Wilayah Jelajah Elang Jawa (Spizaetus bartelsi) di Gunung Salak, Jawa Barat. Bogor: Disampaikan pada seminar Penerapan Sistem Informasi Geografi dan Radio Tracking Untuk Pengelolaan Keanekaragaman Hayati, IPB-Darmaga.

Alfiyasin, M.A. 2018. Potensi Pakan dan Habitat Elang Jawa (Nisaetus bartelsi Stresemann, 1924) Di Bukit Mayana, Kabupaten Kuningan. [skripsi]. Kuningan: Universitas Kuningan.

Becking, J.H. 1989.Henri Jacob Victor Sody (1892-1959): His Life and Work: a Biographical and Bibliographical Study. Leiden: E. J. Brill.

Gjershaug, J.O., N. Røv, T. Nygard, D.M. Prawiradilaga, M.Y. Afianto, Hapsoro, dan A. Supriatna. 2004. Home-Range Size Of The Javan Hawk-Eagle Spizaetus bartelsi Estimated From Direct Observation And Radiotelemetry. J. Raptor Res. 38:343-349.

Harits MRF. 2016. Kajian Persaingan Penggunaan Habitat Antara Elang Jawa dan Sikep-madu Asia di Taman Nasional Bromo Tengger Semeru [skripsi]. Bogor (ID): Institut Pertanian Bogor

Hoogerwerf A. 1949. De Avifauna van Tjibodas En Omgeving, Inclusief Het Natuur-Monument Tjibodas G. Gede. Bogor: Koninklijke Plantentuin van Indonesie.
Kementerian Lingkungan Hidup dan Kehutanan. 2015. SK Dirjen PHKA No. 200/IV/KKH/2015. Kementerian Lingkungan Hidup dan Kehutanan RI. Jakarta.

Kementerian Lingkungan Hidup dan Kehutanan. 2018. Peraturan Menteri Lingkungan Hidup dan Kehutanan Nomor P.92 Tentang Perubahan Atas Peraturan Menteri Lingkungan Hidup Dan Kehutanan Nomor P.20/Menlhk/Setjen/Kum.1/6/2018 Tentang Jenis Tumbuhan dan Satwa Yang Dilindungi. Kementerian Lingkungan Hidup RI. Jakarta.

Kuswandono, Ekawati D, Mulyati S, Murate T, Inoue T, dan Sakaguchi N. 2003. Research And Conservation of Biodiversity In Indonesia (Research on Endangered Species in Gunung Halimun National Park: The Javan Hawk-eagle Spizaetus bartelsi Conservation in Gunung Halimun National Park). Bogor. BCP-JICA.

Meyburg, B.-U., Balen, S. van, Thiollay, J.-M. dan Chancellor, R.D. (1989) Observations on the endangered Java Hawk Eagle Spizaetus bartelsi. Pp. 279-299 in B.-U. Meyburg and R.D. Chancellor, eds. Raptors in the modern World. Berlin, London and Paris: WWG

Nijman V. dan R. Sozer. 1998. Field Identification Of The Javan Hawk Eagle Spizaetus bartelsi. Forktail. 14:13-16

Prawiradilaga, D.M. 1999. Elang Jawa Satwa Langka. Bogor: Biodiversity Conservation Project.

Prawiradilaga, D.M, Murate T, Muzakkir A., Inoue $\mathrm{T}$, Kuswandono, Supriatna Adam A, Ekawati D, Afianto M.Y, Hapsoro, Ozawa T, dan Sakaguchi N. 2003. Panduan Survei Lapangan dan Pemantauan Burung Pemangsa. Jakarta. PT. Binamitra Megawarna.

Prawiradilaga, D.M. 2006. Ecology and Conservation Of Endangered Javan Hawk-eagle Spizaetus bartelsi. Ornithological Science 5. 2:177-186.

Röv, N. Gjershoug, J.O. Prawiradilaga, D.M. Hapsoro dan Supriatna, A. 1997. Conservation Biology of The Javan Hawk-eagle. Bogor. Progress report prepared for the Indonesian Institute of Sciences (LIPI) and The Ministery of State for Environment (KLH).

Setiadi, A.P., Z. Rakhman, P.F. Nurwatha, M. Muchtar dan W. Raharjaningtrah. 2000. Status, Distribution, Population, Ecology and Conservation Javan Hawk-eagle Spizaetus bartelsi, Stresemann 1924 On Southern Part of West Java. Bandung: Final Report BP/FFI/BirdLife International/YPAL-HIMBIO UNPAD. 
Sitorus, D.N. 2016. Studi Habitat Dan Perilaku Burung Pemangsa Famili Accipitridae Di SPTN 1 Tegaldlimo Taman Nasional Alas Purwo, Jawa Timur. [skripsi]. Bogor: Institut Pertanian Bogor. Sozer, R. dan V. Nijman. 1995. Behavioural Ecology, Distribution and Conservation Of The Javan Hawk-Eagle Spizaetus bartelsi Stresemann, 1924. Versl. Tech. Gegevens 62:1-122.

Sozer, R., V. Nijman., I. Setiawan dan Z. Rakhman. 2012. Panduan Inventarisasi Elang Jawa Nisaetus bartelsi. Bogor: Raptor Indonesia. Thiollay JM dan Meyburg BU. 1988. Forest fragmentation and conservation of raptors: survey on the island of Java. Biol. Conserv. 44:229-250. Utami BD. 2002. Kajian potensi pakan elang jawa (Spizaetus bartelsi Stresemann 1924) di Gunung Salak [skripsi]. Bogor (ID): IPB.

Van Balen. S, Nijman, V. dan Sozer, R. 2001. Conservation of the endemic Javan Hawk-Eagle Spizaetus bartelsi Stresemann, 1924: density, age-structure and population numbers. Contrib. Zool. 70:161-173.
Van Balen. S, V. Nijman, dan R. Sozer. 1999. Distribution And Conservation Of The Javan Hawk-Eagle Spizaetus bartelsi. Bird Conservation International . 9:333-349.

Widodo, Tri. 2004. Populasi dan Wilayah Jelajah Elang Jawa (Spizaetus bartelsi Stresmann, 1924) di Gunung Kendeng Resort Cikaniki Taman Nasional Gunung Halimun. [skripsi]. Bogor: Institut Pertanian Bogor. 